\title{
Soil moisture temporal stability analysis for typical hilly and gully re-vegetated catchment in the Loess Plateau, China
}

\author{
Shuai Wang ${ }^{1,2} \cdot$ Bojie Fu ${ }^{1,2} \cdot$ Jianbo Liu ${ }^{1,2}$
}

Received: 8 December 2015/Accepted: 19 March 2016/Published online: 27 April 2016

(C) Springer-Verlag Berlin Heidelberg 2016

\begin{abstract}
In arid and semi-arid regions, soil moisture in particular is a key integrative state variable that is linked to a range of hydrological, ecological, climatic, and geological processes; however, it is usually highly variable in space and time. To overcome this issue, it is necessary to study the temporal stability of soil moisture. Here, we intend to take a soil moisture temporary stability analysis for the typical hilly and gully re-vegetated areas in the Loess Plateau. Using cumulative frequency distribution, the relative difference, and Spearman's rank correlation coefficient to conduct temporal stability analysis for the soil moisture at five slope transects of a typical hilly and gully re-vegetated loess catchment during the rainy season of 2012. We found the soil moisture spatial distribution pattern for the small, typical hilly and gully re-vegetated Loess Plateau catchment to be stable. However, it is not always easy to find sites representative of the catchment average moisture content under different conditions; but it is easier to find sites with extremely high water content in the slopes. A new method for identifying temporally stable locations in typical re-vegetated hilly and gully loess areas is needed. The relationships between soil moisture and other catchment conditions for the diagnosis of representative sites must also be determined. The pattern
\end{abstract}

Bojie Fu

bfu@rcees.ac.cn

Shuai Wang

shuaiwang@rcees.ac.cn

1 State Key Laboratory of Urban and Regional Ecology, Research Center for Eco-Environmental Sciences, Chinese Academy of Sciences, Beijing 100085, China

2 Joint Center for Global Change Studies, Beijing 100875, China stability and type stability of soil moisture guarantees that sampling comparisons in this area can be conducted at different times to compare the differences between various land cover types, especially with regard to deep soil depth.

Keywords Land cover - Re-vegetation - Loess plateau . Soil moisture $\cdot$ Temporal stability

\section{Introduction}

Soil moisture in particular is a key integrative state variable that is linked to a range of hydrological, ecological, climatic, and geological processes (Qiu et al. 2001; Legates et al. 2010). Soil moisture is also highly variable in space and time due to the high nonlinearity and complex feedback mechanisms among different controlling factors and processes $(\mathrm{Hu}$ et al. 2010a). To overcome this issue, there has been growing interest in studying the temporal stability of soil moisture (Wang 2014; Wang et al. 2015), which was first defined by Vachaud et al. (1985) as the time invariant association between spatial location and statistical parametric values on the basis of the probability density of soil moisture. Temporal stability is also often referred to as time stability, but other terms, such as rank stability and order stability, have also been proposed and discussed (Chen 2006).

The number of publications on soil moisture temporal stability has recently undergone a period of accelerated growth (Vanderlinden et al. 2012). Information on temporal stability has also found multiple applications, such as identifying representative locations, optimizing monitoring schemes, filling in missing data, scaling soil moisture content, improving the performance of hydrological models, and delineating water management zones (Wang 2014). Optimizing the sampling strategy for the sake of 
reducing the level of uncertainty in the estimation of soil moisture distribution is not only beneficial to the determination and construction of efficient networks of stations (Van Pelt and Wierenga 2001; Martinez-Fernandez and Ceballos 2003), but could also be effectively combined with remote sensing to improve the precision of soil moisture estimation as well as to calibrate and validate the confidence degree (Mohanty and Skaggs 2001; Jacobs et al. 2004). Due to the wide application of the temporal stability concept and approach based on the probability density function of soil moisture under many different climatic conditions, Brocca et al. (2009, 2010) systemically summarized the characteristics of the temporal stability of soil moisture and its influential factors, including topography, precipitation, and vegetation in addition to soil texture (Grayson and Western 1998; Mohanty and Skaggs 2001).

The Loess Plateau in China is a region representative of a typical area that experiences a water deficiency, and is an ideal area to research the dynamics of soil moisture in response to natural and anthropological influences, as large scale re-vegetation programmes have been implemented since 1980s in this area. A series of studies on the time stability of soil moisture in the northern Loess Plateau have been conducted for different purposes (Hu et al. 2009, 2012; Gao and Shao 2012; Jia and Shao 2013; Gao et al. 2015). The earliest study was conducted by $\mathrm{Hu}$ et al. (2009), who explored the effects of neutron probe calibration procedures on the identification of the most time stable location for mean soil moisture estimation. Subsequently, Hu et al. (2010a) developed a new index termed the mean absolute bias error for soil moisture temporary stability analysis. Thereafter, they explored the impacts of soil depth, soil texture, and land use on the time stability of soil moisture (Hu et al. 2010b) and compared the performance of seven time stability indices (Hu et al. 2012). Recently, the time stability concept has been extended to an adjacent or distant area for the estimation of mean soil moisture, and has also been applied in diverse soil layers (Gao and Shao 2012; Jia and Shao 2013; Gao et al. 2013, 2015). However, nearly all these studies were concentrated in the transitional belt between loess and desert; studies conducted in typical hilly and gully areas of the Loess Plateau are rare.

Following the implementation of the Grain-for-Green project for over 10 years, most of the cultivated lands on the slope in the Loess Plateau were planted with forests and shrubs, though grasses, in some cases succeeding to subshrubs, were also grown on some abandoned cultivated lands. These re-vegetated communities influence soil moisture recharge and usage processes. Wang et al. (2012, 2013) identified soil moisture replenishment, retention, and flux variations under tree, shrub, subshrub, grass, and corn cover in the catchment of the Loess Plateau. The different land cover types clearly influenced the water input and output amounts in the re-vegetated area. Soil particle size and soil organic matter content were also recognized as the influencing factors for moisture spatial variability (Hu et al. 2009). Vegetation restoration programs have thus complicated the spatiotemporal distribution of soil moisture. A temporary stability analysis needs to be conducted for the soil moisture in the typical hilly and gully re-vegetated areas in the Loess Plateau.

This study, therefore, aimed to investigate the temporal stability of the spatial patterns for soil moisture content along the soil profiles and to identify representative locations of each soil layer for future prediction of the mean soil moisture of this typical hilly and gully loess area.

\section{Materials and methods}

\section{Site description}

The experiment was conducted in the Yangjuanggou watershed $\left(36^{\circ} 42^{\prime} \mathrm{N}, 109^{\circ} 31^{\prime} \mathrm{E}, 2.02 \mathrm{~km}^{2}\right)$, which is located in the central part of the Loess Plateau in Shaanxi Province, China. It is also representative of the geomorphology of the hilly and well-developed gullies in the central Loess Plateau. The climate at this study site is typically arid and semiarid, which is influenced by the combination of the North China monsoon and northwest arid climatic conditions. Precipitation mainly occurs between June and September, amounting to $\sim 535 \mathrm{~mm}$ per year, and displays significant inter-annual variability (Wang et al. 2013). The average temperature of the study region was $\sim 10.6^{\circ} \mathrm{C}$ over the past 20 years. Loessial soil, one kind of Calcic Cambisols in the study area is representative of the Loess Plateau. Its specific properties are a uniform texture, high porosity, and high erosivity (Zhou et al. 2015). The distribution range of vegetation in the study site was classified as a forest-steppe vegetation area. With the aim of soil and water conservation, the Grain-for-Green policy was widely implemented in the Loess Plateau after 1999 by abandoning cultivated lands on steep slopes for re-vegetation. As a result, a large amount of vegetation was introduced in the research region, including Robini apseudoacacia Linn, Platycladus orientalis, Sophora davidii, Lespedeza davurica, and Amorpha fruticosa, among others. Details of the study site have also been documented by Wang et al. (2012, 2013, 2016).

\section{Soil moisture sampling transects and soil moisture sampling}

Five slope transects (Slope1, Slope2, Slope3, Slope4, and Slope5; Fig. 1) were established in this $\sim 2 \mathrm{~km}^{2}$ watershed, with lengths of $\sim 350,300,300,400$, and $400 \mathrm{~m}$, 
Fig. 1 The general situation of Yangjuangou watershed and pictures of sampling sites
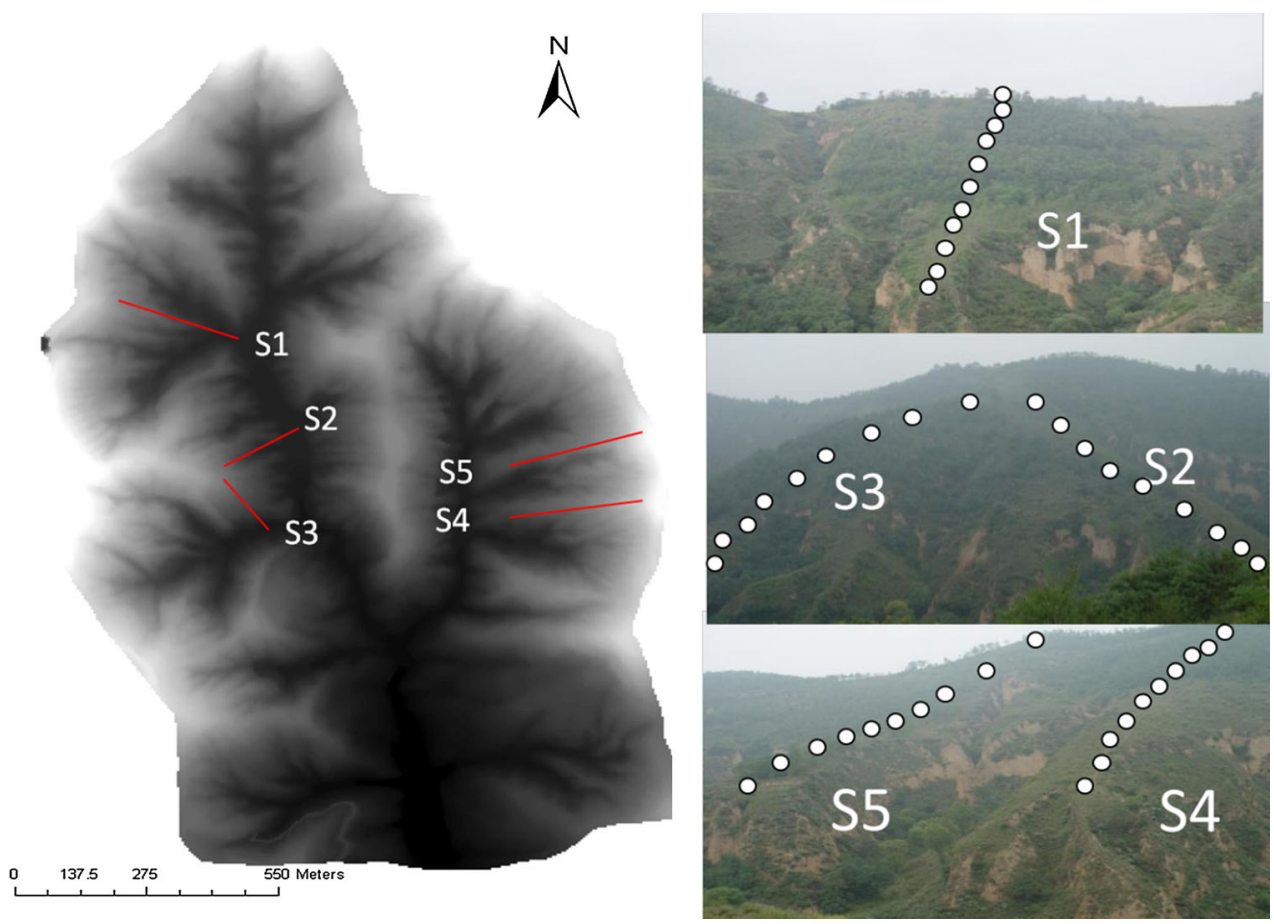

respectively, to sample soil moisture. There were 11, 9, 9, 12, and 11 sampling points along the transects of Slope 1, Slope 2, Slope 3, Slope 4, and Slope 5, respectively (Fig. 1). Soil moisture was sampled at these points at depths of $0-180 \mathrm{~cm}$ at $10-\mathrm{cm}$ intervals during the period from May 15 to September 23, 2012.

During the entire sampling period, 12 sampling occasions were taken in total. Soil moisture values for all depths were sampled using a portable time domain reflectometry (TDR) system (TRIME-PICO IPH/T3; IMKO, Germany), consisting of a TRIMEIPH probe, a TRIME-Data Pilot data logger, and fiber glass access tubes $(\phi=40 \mathrm{~mm})$. On each sampling occasion, soil moisture was sampled within $4 \mathrm{~h}$. During such short times, the temporal variation in soil moisture was expected to be negligible. A hand auger $(\phi=45 \mathrm{~mm})$ was used to install fiber glass access tubes rather than the original accessories for installing tubes. To facilitate installation of the tubes, the relief at some sampling points was slightly disturbed. Each site was set described above at the end of April 2011, and measurements were begun two months later to allow the soil to settle. The TRIMETDR system has been shown to provide accurate soil moisture measurements in the Loess Plateau region after local calibration ( $\mathrm{Li}$ et al. 2005; Gao et al. 2011; Wang et al. 2016).

These five slope transects have different land cover combinations (land cover types from the foot to the top of the hillslope). Slope 1 is: young plantation + old plantation + grass; slope 2 is: subshrub + young plantation + grass; slope 3 is: old plantation + young plantation + grass; slope 4 is: shrub + grass + old plantation; and slope 5 is: young plantation + shrub + grass. The grasses are mainly Artemisia Linn, couch grass, and small weed, and the shrubs are Prunus armeniaca and Hippophae rhamnoides in the mature forest and Robini apseudoacacia in the young forest. All vegetation replaced former farmland. The shape and gradient of slopes 1, 4, and 5 are similar. But the aspect of slope 1 is opposite of the other two. Slope 2 and 3 also have a similar shape and gradient but different aspect (Table 1) (Wang et al. 2016).

\section{Method of data analysis}

Three techniques are usually used for the analysis of soil moisture temporal stability-cumulative frequency distribution, relative difference analysis, and the nonparametric Spearman's rank correlation test. Let $M$ be the number of sampling campaign, $N$ be the number of observing locations, and $\theta_{i j}$ be the rank of soil moisture content at the location of $i$ and the $j$ sampling campaign, and $\theta_{i 1}$ is the rank of soil moisture observed at the same location but for one sampling campaign (Hu et al. 2009).

The Spearman rank correlation coefficient $\left(r_{\mathrm{s}}\right)$ is calculated as follows:

$r_{\mathrm{s}}=1-6 \sum_{i=1}^{N} \frac{\left(\theta_{i j}-\theta_{i l}\right)^{2}}{N\left(N^{2}-1\right)}$

The closer the value is to 1 , the more stable the analyzed process. 
Table 1 Topographical attributes and the land cover types of the sample sites (Wang et al. 2016)

\begin{tabular}{|c|c|c|c|c|c|c|}
\hline Slope & Site & Aspect & Cos(aspect) & Gradient $\left({ }^{\circ}\right)$ & Cover type & Comment \\
\hline $\mathrm{S} 1$ & A1 & East & -0.173 & 21 & Young plantation & $<5$ years, bottom of the slop \\
\hline $\mathrm{S} 1$ & A2 & East & -0.173 & 21 & Young plantation & $<5$ years \\
\hline $\mathrm{S} 1$ & A3 & East & -0.173 & 21 & Young plantation & $<5$ years \\
\hline S1 & A4 & East & -0.173 & 16 & Young plantation & $<5$ years \\
\hline $\mathrm{S} 1$ & A5 & East & -0.173 & 22 & Young plantation & $\begin{array}{l}<5 \text { years, more dense, transition zone between } \\
\text { young plantation and old plantation }\end{array}$ \\
\hline $\mathrm{S} 1$ & A6 & East & -0.173 & 16 & Old plantation & $>25$ years \\
\hline S1 & A7 & East & -0.173 & 31 & Old plantation & $>25$ years \\
\hline S1 & A8 & East & -0.173 & 36 & Old plantation & $>25$ years \\
\hline $\mathrm{S} 1$ & A9 & East & -0.173 & 39 & Old plantation & $>25$ years, gully bank \\
\hline $\mathrm{S} 1$ & A10 & East & -0.173 & 39 & Old plantation & $>25$ years, gully bank \\
\hline $\mathrm{S} 1$ & A11 & - & - & 0 & Grassland & Mountain top \\
\hline $\mathrm{S} 2$ & B1 & Northeast & 0.574 & 16 & Subshrub & Bottom of the slop \\
\hline $\mathrm{S} 2$ & B2 & Northeast & 0.574 & 12 & Subshrub & - \\
\hline $\mathrm{S} 2$ & B3 & Northeast & 0.574 & 14 & Shrub & - \\
\hline $\mathrm{S} 2$ & B4 & Northeast & 0.707 & 36 & Young plantation & Higher and with dense herbs \\
\hline $\mathrm{S} 2$ & B5 & Northeast & 0.707 & 34 & Young plantation & Higher and with dense herbs \\
\hline $\mathrm{S} 2$ & B6 & Northeast & 0.707 & 27 & Young plantation & Dense herbs \\
\hline $\mathrm{S} 2$ & B7 & Northeast & 0.707 & 26 & Young plantation & Dense herbs \\
\hline $\mathrm{S} 2$ & B8 & Northeast & 0.707 & 24 & Grassland & Sparse \\
\hline $\mathrm{S} 2$ & B9 & Northeast & 0.707 & 34 & Grassland & - \\
\hline S3 & $\mathrm{C} 1$ & Southeast & -0.706 & 28 & Old plantation & $>30$ years \\
\hline $\mathrm{S} 3$ & $\mathrm{C} 2$ & Southeast & -0.706 & 33 & Old plantation & $>30$ years \\
\hline S3 & $\mathrm{C} 3$ & Southeast & -0.706 & 37 & Old plantation & $>30$ years \\
\hline S3 & $\mathrm{C} 4$ & Southeast & -0.706 & 38 & Old plantation & $>30$ years \\
\hline S3 & $\mathrm{C} 5$ & Southeast & -0.706 & 32 & Old plantation & $>30$ years \\
\hline S3 & C6 & Southeast & -0.706 & 21 & Old +youngplantation & - \\
\hline S3 & $\mathrm{C} 7$ & Southeast & -0.706 & 12 & Grassland & Sparse \\
\hline S3 & $\mathrm{C} 8$ & Southeast & -0.706 & 10 & Grassland & Sparse \\
\hline S3 & C9 & Southeast & -0.706 & 8 & Grassland & Dense \\
\hline S4 & D1 & Southwest & -0.344 & 8 & Shrub & Sparse \\
\hline S4 & D2 & Southwest & -0.344 & 16 & Shrub & Sparse \\
\hline S4 & D3 & Southwest & -0.344 & 21 & Shrub & Sparse \\
\hline S4 & D4 & Southwest & -0.344 & 16 & Shrub & Sparse \\
\hline S4 & D5 & Southwest & -0.344 & 8 & Orchard & \\
\hline S4 & D6 & Southwest & -0.344 & 16 & Grassland & Sparse \\
\hline $\mathrm{S} 4$ & D7 & Southwest & -0.344 & 26 & Subshrub + grassland & $\begin{array}{l}\text { Transition zone between grassland and old } \\
\text { plantation }\end{array}$ \\
\hline $\mathrm{S} 4$ & D8 & Southwest & -0.344 & 34 & Old plantation & $>30$ years \\
\hline S4 & D9 & Southwest & -0.344 & 35 & Old plantation & $>30$ years \\
\hline S4 & D10 & Southwest & -0.344 & 35 & Old plantation & $>30$ years \\
\hline S4 & D11 & Southwest & -0.344 & 35 & Old plantation & $>30$ years, gully bank \\
\hline S4 & D12 & - & - & - & Grassland & Mountain top \\
\hline S5 & E1 & Southwest & -0.344 & 8 & Young plantation & Terrace land \\
\hline S5 & E2 & Southwest & -0.344 & 5 & Young plantation & Terrace land \\
\hline S5 & E3 & Southwest & -0.344 & 5 & Young plantation & Terrace land \\
\hline S5 & E4 & Southwest & -0.344 & 0 & Young plantation & Terrace land \\
\hline S5 & E5 & Southwest & -0.344 & 0 & Young plantation & Terrace land \\
\hline S5 & E6 & Southwest & -0.344 & 0 & Young plantation & Terrace land \\
\hline
\end{tabular}


Table 1 continued

\begin{tabular}{|c|c|c|c|c|c|c|}
\hline Slope & Site & Aspect & Cos(aspect) & Gradient $\left({ }^{\circ}\right)$ & Cover type & Comment \\
\hline S5 & E7 & Southwest & -0.344 & 0 & Young plantation & Terrace land, with silt pit \\
\hline S5 & E8 & Southwest & -0.344 & 0 & Shrub & Dense \\
\hline S5 & E9 & Southwest & -0.344 & 0 & Shrub & Dense \\
\hline S5 & E10 & Southwest & -0.344 & 0 & Young plantation & Terrace land, with silt pit \\
\hline S5 & E11 & - & - & - & Grassland & Mountain top \\
\hline
\end{tabular}

The temporal mean relative difference $\overline{\delta_{i}}$ and its standard deviation $\sigma\left(\delta_{i}\right)$ are defined as follows:

$\overline{\delta_{i}}=\frac{1}{M} \sum_{j=1}^{M} \delta_{i j}$

$\sigma\left(\delta_{i}\right)=\sqrt{\frac{1}{M-1} \sum_{j=1}^{M}\left(\delta_{i j}-\overline{\delta_{i}}\right)^{2}}$

Where $\delta_{\mathrm{ij}}$ is the relative difference of soil moisture for location $i$ between the mean soil moisture of all the sampling locations at the $j$ sampling campaign. Values of $\overline{\delta_{i}}$ near zero at locations indicate that their soil moisture content are close to the mean value of the study area, whereas other locations with $\overline{\delta_{i}}$ higher or lower than zero are over or underestimating, respectively, the mean of the area. Locations with low values of $\sigma\left(\delta_{i}\right)$ are considered to be temporally stable. Thus, it is mainly used to identify locations that systematically represent the average soil moisture of the study area.

The cumulative frequency distribution for each sampling campaign is used to find sites near the $50 \%$ level of the distribution, and these points can represent the average conditions of the study area. Similarly, the cumulative frequency distribution can also be used to determine the drier and wetter sites under different water conditions.

\section{Results}

\section{Stability of soil moisture spatial patterns in the catchment}

All the average rank correlation coefficients of the soil moisture at four different depths $(0-40,40-100,100-180$, and $0-180 \mathrm{~cm})$ are greater than 0.45 , and reached a significant level $(P<0.05)$ (Fig. 2). This finding suggests that the spatial patterns of the soil moisture distribution in this small catchment are similar in different occasions. The temporary dynamic of the value of the rank correlation coefficient of the soil moisture in these different

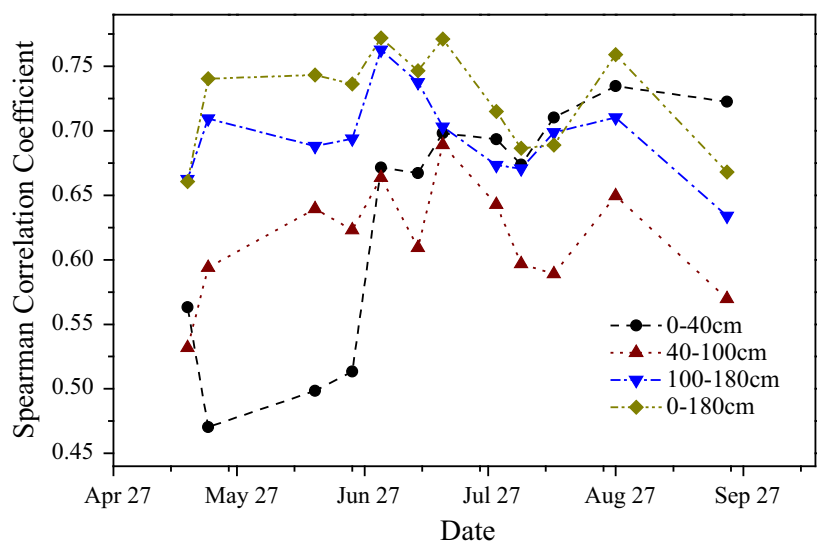

Fig. 2 Mean Spearman's rank correlation coefficients corresponding to different time lags for the four depths soil moisture

depths shows a deep layer with a higher spatial structure stability. Surface $(0-40 \mathrm{~cm})$ soil moisture is lower in early observations and also with lower rank correlation coefficient values. With the rainy season, the soil water replenished, making the surface moisture content uniform and causing the rank correlation coefficient to rise. However, the values for the depth of $40-100 \mathrm{~cm}$ is reduced, as this is a critical zone in which different land use types influence water input and output processes (Wang et al. 2012).

\section{Representative sites based on relative difference analysis}

According to the temporal mean relative difference $\overline{\delta_{i}}$ (Fig. 3) and its standard deviation $\sigma\left(\delta_{i}\right)$ of the surface layer $(0-40 \mathrm{~cm})$, there are six sites with values of $\overline{\delta_{i}}$ within $\pm 1 \%$, including $\mathrm{A} 6, \mathrm{~B} 14, \mathrm{C} 7, \mathrm{~B} 13, \mathrm{E} 9$, and $\mathrm{D} 9$; the maximum ten sites include B5, E11, E3, C6, E10, B7, D1, E6, D6, and B6; and the minimum ten sites include A1, C3, B9, A5, C1, E2, A4, A7, D11, and C2. For the layer with a depth of 40-100 cm, there are only two sites with values of $\overline{\delta_{i}}$ within $\pm 1 \%$, namely, D1 and $\mathrm{C} 4$; the maximum ten sites include B3, E8, E3, B14, B8, D6, B7, E4, B10, and B6; and the minimum ten sites include $\mathrm{A} 1, \mathrm{C} 2, \mathrm{C} 3, \mathrm{~B} 12$, 

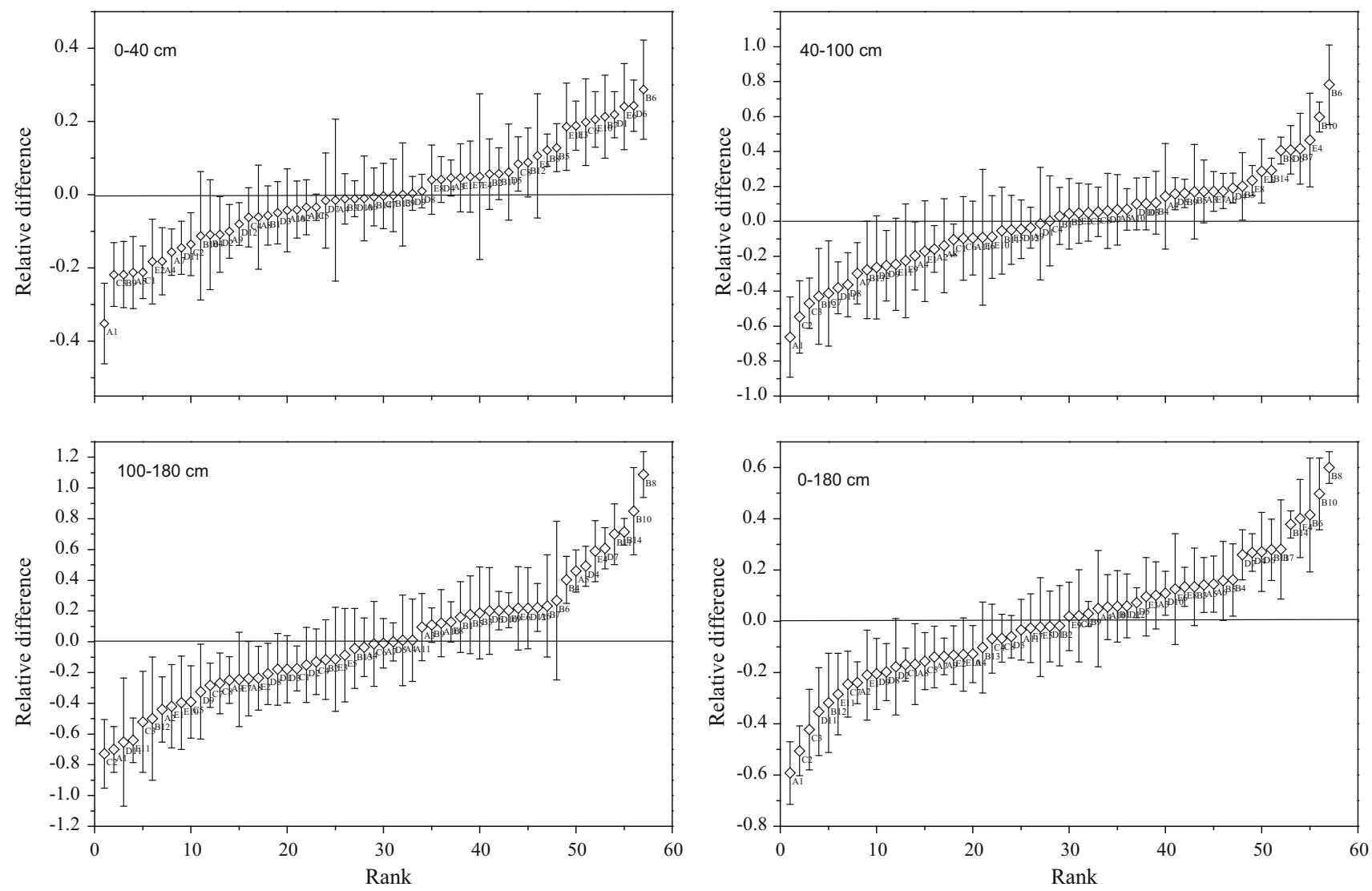

Fig. 3 Ranked mean relative differences with their standard deviations for soil moisture in the depth of 0-40 cm, 40-100 cm, 100-180 cm and $0-180 \mathrm{~cm}$

C7, D11, D8, A7, B13, and D2. For the layer with a depth of $100-180 \mathrm{~cm}$, there are only three sites with values of $\overline{\delta_{i}}$ within $\pm 1 \%$, namely, A7, D5, and A4; the maximum ten sites include B6, B4, A5, D4, E4, D7, B11, B14, B10, and $\mathrm{B} 8$, and the minimum ten sites include $\mathrm{C} 2, \mathrm{~A} 1, \mathrm{D} 11, \mathrm{E} 11$, C3, B12, A2, E1, E10, and C5. For the entire average soil moisture depth profile of $0-180 \mathrm{~cm}$, there are eight sites with values of $\overline{\delta_{i}}$ within $\pm 1 \%$, including $\mathrm{C} 4, \mathrm{C} 8, \mathrm{D} 3, \mathrm{~A} 11$, $\mathrm{E} 7, \mathrm{E} 5, \mathrm{D} 1$, and $\mathrm{B} 2$; the maximum ten sites include D7, D4, D6, B11, B7, B14, E4, B6, B10, and B8; and the minimum ten sites include A1, C2, C3, D11, B12, E11, C7, $\mathrm{A} 2$, E1, and D9. Of the sites with values of $\overline{\delta_{i}}$ within $\pm 1 \%$ in the four different layers, only the $\mathrm{C} 4$ site was repeated in the depth profile of $40-100 \mathrm{~cm}$ and the depth profile of 0-180 cm. However, in the driest ten sites, four sites-A1, C2, C3, and D11-appeared in all four different depths. The B6 site always remained in the ten wettest sites in the four depths, and the D6 and B7 sites are the wettest in the three depths except in the depth of 100-180 cm, while E3 site is the wettest site in the two surface layers (Table 1).

\section{Representative sites based on cumulative frequency distribution analysis}

For all four layers, we chose the sampling campaign of May 15 which is at the beginning of the rainy season as the dry period and of September 23 as the wet period which is at the end of the rainy season, and the average content of all the 2012 sampling campaigns was subjected to a total of three cumulative frequency distribution analyses. For the surface layer with a depth of $0-40 \mathrm{~cm}$, the average soil moisture of these three occasions amounted to 13.1, 16.7, and $13.2 \mathrm{~cm}^{3} \mathrm{~cm}^{-3}$. The five sites near the $50 \%$ level of the distribution on May 15 are C5, B14, D7, A3, and C6; on September 23, they are D2, E8, B11, B2, and D4; and for the entire 2012 observation period are C7, D9, D8, E9, and A3. For the middle layer, which is $40-100 \mathrm{~cm}$ in depth, the average soil moisture of these three occasions amount to $9.4,12.5$, and $10.0 \mathrm{~cm}^{3} \mathrm{~cm}^{-3}$. The five sites near the $50 \%$ level of the distribution on May 15 are B13, B9, A3, D5, and E3; on September 23 are D4, B2, D12, E7, and E5; 
Fig. 4 The soil moisture in four depths cumulative probability distribution during the 2012 observation period
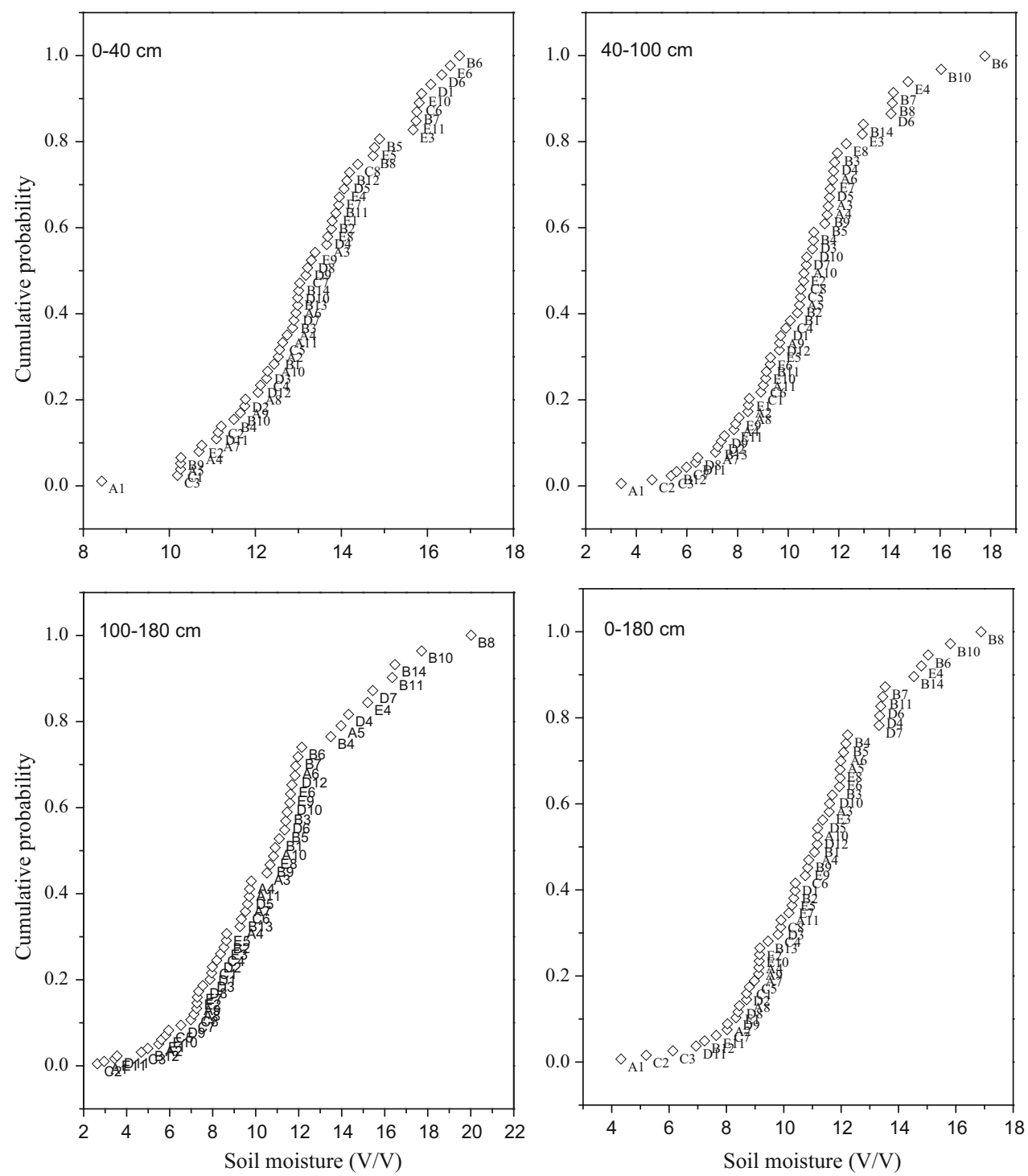

and for the entire 2012 observation period are C8, E2, A10, D7, and D10. For the deep layer with a depth of $100-180 \mathrm{~cm}$, the average soil moisture for these three occasions amounted to $10.6,9.4$, and $9.6 \mathrm{~cm}^{3} \mathrm{~cm}^{-3}$. The five sites near the $50 \%$ level of the distribution on May 15 are B6, D6, D11, D10, and D4; on September 23 are D1, E5, E8, B4, and B9; and for the entire 2012 observation period are B9, E8, A10, B1, and B5. For the whole $0-180 \mathrm{~cm}$ depth profile, the average soil moisture of these three occasions amounts to $1.8,12.0$, and $10.1 \mathrm{~cm}^{3} \mathrm{~cm}^{-3}$. The five sites near the $50 \%$ level of the distribution on May 15 are E9, D3, D11, C4 and B9; on September 23 are A3, B4, B9, A5, and D5; and for the entire 2012 observation period are B9, A4, B1, D12, and A10. Only the B9 site appears in the three occasions of the 0-180 layer, with no recurring sites in other layers (Fig. 4).
Discussions

\section{Soil moisture spatial pattern stability in the catchment}

Rank correlation coefficient analysis indicates that the soil moisture content has significantly similar spatial patterns in four layers during the observed period with the deepest layer with a depth of $100-180 \mathrm{~cm}$ being the most stable. Compared with the results for the northern Loess Plateau, in which there is a transitional belt between loess and desert (Hu et al. 2010a), the soil moisture spatial distribution pattern in the typical loess hilly and gully areas is less stable. The rank correlation coefficient of the northern plateau is over 0.82 and has reached a very significant level $(P<0.01)$, although the soil texture here is more uniform 
(Hu et al. 2010a). Meanwhile, with the increase in depth in the profile, there is also a characteristic feature of "irregularly changing", "regularly changing", and "relatively constant", respectively (Gao et al. 2015). These findings are the result of the more complex terrain and heterogeneity of this study area, as well as the greater rainfall here than the northern Loess Plateau. And with the observation period in the rainy season, precipitation is frequent, and water budget processes are active, causing fluctuations in moisture (Wang et al. 2013).

Because the small watershed has spatial heterogeneity in terms of land cover and soil texture, result in water movement in depth is also spatial heterogeneous. For the subsurface layer at a depth of 40-100 cm under conditions of heavy rainfall, water may reach up to $100 \mathrm{~cm}$ down in the soil layer; under conditions of less rainfall, extensive vegetation restoration may intercept rainfall before it can reach the soil (Wang et al. 2013). The frequent and intense influence of environmental factors results in the soil moisture spatial pattern in the layer being relatively unstable during the rainy season. For this reason, the temporal mean relative difference analysis also resulted in varying depths of a profile, which was also found in the study conducted by $\mathrm{Hu}$ et al. (2010b). The finding implies that the stable or representative site in a particular layer or depth of the catchment cannot represent other depths due to the spatial heterogeneity of the soil moisture profile. Also, relevant is the smaller gap between the moisture content of sample sites with a large sample size.

\section{Representative stability sites of the catchment}

The above analysis indicates that the soil moisture spatial distribution pattern of a catchment has temporary stability, but it is usually difficult to find a common representative sample of the different layers. For the entire 0-180 cm soil profile, based on relative difference analysis, the drier sites of the catchment are all located in the old plantations on the sunny slope, while the wetter sites are found in the shrub and grass sites on the shady slope. These findings are consistent with vegetation effects on soil moisture in the Loess Plateau (Fu et al. 2003; Chen et al. 2007). Similarly, the representative sites, based on cumulative frequency distribution analysis, in four depths in the drier period, wetter period, and throughout the observation season are different. However, the B9 site can be identified as a common representative site in the $0-180 \mathrm{~cm}$ layer in all three observation periods. The site consists of abandoned farmland mixed with grasses and shrubs at the top of a shady slope. In addition, the higher moisture content sites of the samples in the three observation periods are relatively stable, which implies that this method can be used to find the wetter sites easily. It is worth noting that the representative sites obtained by relative difference analysis and cumulative frequency distribution analysis are also inconsistent. This inconsistency is associated with small differences in the soil moisture content between sample sites during the observation period, which is also affected in the temporary stability analysis method. Hu et al.(2010b) expounded the problems associated with using this method to estimate mean soil moisture content, considering the constant relative differences in stable locations as suggested by Grayson and Western (1998), and developed an index of mean absolute bias error to identify temporally stable locations.

\section{Implications for typical re-vegetated hilly and gully loess areas}

Soil moisture acts as a crucial factor in vegetation production in the Loess Plateau and has garnered a great deal of attentions in recent decades (Yao et al. 2012; Wang et al. 2012, 2013; Zhou et al. 2015). However, manual sampling is difficult and time consuming, making it ill suited for large scale studies. In addition, in the complex broken terrain of the Loess Plateau, soil moisture remote sensing inversion products errors tend to be larger. Therefore, the recognition of temporally stable locations with respect to soil water content is of considerable importance for the prediction of the general regional average moisture condition, especially in the re-vegetated catchments in typical hilly and gully areas. The soil moisture content patterns of the various vegetation types in the semiarid area of the Loess Plateau have been extensively researched and documented over the past several decades, including the vertical profile characteristics (Qiu et al. 2001; Fu et al. 2003; Chen et al. 2007). The infiltration and diminishing processes of the soil water of typical land covers in this area have also been well documented during the rainy season, and there exist stable type of soil moisture in this area (Wang et al. 2012, 2013). This study confirms that stable patterns exist in this catchment, and representative sites can be found in different layers to diagnose pulses of soil moisture. However, the inconsistencies of the results of relative difference analysis and cumulative frequency distribution analysis remind us of the need to develop a new method for identifying temporally stable locations for this typical re-vegetated hilly and gully loess area.

Catchments are complex systems that are subject to a variety of influences, including water as an important driving force. Analysis of the soil moisture of a site that is representative of the catchment can inform researchers of the whole basin's hydrological, ecological, climatic, and even geological processes; nevertheless, further analysis is required to determine the relationship between them. 


\section{Conclusions}

Using the three typical pieces of time stability analysis equipment, cumulative frequency distribution, the relative difference, and Spearman's rank correlation coefficient; we found the spatial distribution pattern of soil moisture in the small catchment to be stable. This finding implies that there exist pattern stability and type stability for the soil moisture in the typical re-vegetated hilly and gully areas of the Loess Plateau catchment. Pattern stability and type stability allows us to compare soil moisture differences between land cover types in this area, even during the rainy season. However, due to the frequent precipitation during the observation period, the gap between the soil moisture content of different sites gradually narrowing, as well as the defects of the traditional time stability analysis method, it is not easy to find sites that are representative of the catchment average moisture content under different conditions. It is, however, easier to find sites with extremely high water content in the slopes. It is also necessary to determine the relationships between soil moisture and other catchment conditions for the diagnosis from represent site.

Acknowledgments This work was funded by the National Natural Science Foundation of China (No. 41401027, 41390464).

\section{References}

Brocca L, Melone F, Moramarco T, Morbidelli R (2009) Soil moisture temporal stability over experimental area in Central Italy. Geoderma 148:364-374

Brocca L, Melone F, Moramarco T, Morbidelli R (2010) Spatialtemporal variability of soil moisture and its estimation across scales. Water Resour Res 46:W02516. doi:10.1029/ 2009WR008016

Chen Y (2006) Letter to the editor on "rank stability or temporal stability". Soil Sci Soc Am J 70:306

Chen LD, Huang ZL, Gong J, Fu BJ, Huang YL (2007) The effect of land cover/vegetation on soil water dynamic in the hilly area of the loess plateau, China. Catena 70:200-208

Fu BJ, Wang J, Chen L, Qiu Y (2003) The effects of land use on soil moisture variation in the Danangou catchment of the Loess Plateau, China. Catena 54:197-213

Gao L, Shao MA (2012) Temporal stability of soil water storage in diverse soil layers. Catena 95:24-32

Gao XD, Wu PT, Zhao XN, Shi YG, Wang JW et al (2011) Soil moisture variability along transects over a well-developed gully in the Loess Plateau, China. Catena 87:357-367

Gao XD, Wu PT, Zhao XN, Zhou X, Zhang BQ et al (2013) Estimating soil moisture in gullies from adjacent upland measurements through different observation operators. J Hydrol 486:420-429

Gao L, Shao MA, Peng XH, She DL (2015) Spatio-temporal variability and temporal stability of water contents distributed within soil profiles at a hillslope scale. Catena 132:29-36

Grayson RB, Western AW (1998) Towards areal estimation of soil water content form point measurements: time and space stability of mean response. J Hydrol 207:68-82
Hu W, Shao MA, Wang QJ, Reichardt K (2009) Time stability of soil water storage measured by neutron probe and the effects of calibration procedures in a small watershed. Catena 79:72-82

$\mathrm{Hu}$ W, Shao MA, Han FP, Reichardt K, Tan J (2010a) Watershed scale temporal stability of soil water content. Geoderma 158:181-198

Hu W, Shao MA, Reichardt K (2010b) Using a new criterion to identify sites for mean soil water storage evaluation. Soil Sci Soc Am J 74:762-773

$\mathrm{Hu}$ W, Tallon LK, Si BC (2012) Evaluation of time stability indices for soil water storage upscaling. J Hydrol 475:2229-2241

Jacobs JM, Mohanty BP, En-Ching H, Miller D (2004) SMEX02: filed scale variability, time stability and similarity of soil moisture. Remote Sens Environ 92:436-446

Jia YH, Shao MA (2013) Temporal stability of soil water storage under four types of revegetation on the northern Loess Plateau of China. Agr. Water Manage 117:33-42

Legates DR, Mahmood R, Levia DF, DeLiberty TL, Quiring SM et al (2010) Soil moisture: a central and unifying theme in physical geography. Prog Phys Geog 35:65-86

Li XY, Bi HX, Diao YM, Liu LF, Li GX et al (2005) The measurement principles of TRIME-TDR system and its application in Caijiachuan watershed of Loess Plateau, China. Science Soil Water Conserv 3:112-115 (in Chinese with English abstract)

Martinez-Fernandez J, Ceballos A (2003) Temporal stability of soil moisture in a large-field experiment in Spain. Soil Sci Soc Am J 67:1647-1656

Mohanty BP, Skaggs TH (2001) Spatio-temporal evolution and timestable characteristics of soil moisture within remote sensing footprint with varying soil, slope, and vegetation. Adv Water Resour 24:1051-1067

Qiu Y, Fu BJ, Wang J, Chen LD (2001) Soil moisture variation in relation to topography and land use in a hillslope catchment of the Loess Plateau. China. J Hydrol 240(3-4):243-263

Vachaud G, Silans APDE, Balabanis P, Vauclin M (1985) Temporal stability of spatially measured soil water probability density function. Soil Sci Soc Am J 49:822-828

Van Pelt RS, Wierenga PJ (2001) Temporal stability of spatially measured soil water matric potential probability density function. Soil Sci Soc Am J 65:668-677

Vanderlinden K, Vereecken H, Hardelauf H, Herbst M, Martinez G et al (2012) Temporal stability of soil water contents: a review of data and analyses. Vadose Zone J. doi:10.2136/vzj2011.0178

Wang TJ (2014) Modeling the impacts of soil hydraulic properties on temporal stability of soil moisture under a semi-arid climate. J Hydrol 519:1214-1224

Wang S, Fu BJ, Gao GY, Yao XL, Zhou J (2012) Soil moisture and evapotranspiration of different land cover types in the Loess Plateau, China. Hydrol Earth Syst Sci 16:2883-2892

Wang S, Fu BJ, Gao GY, Liu Y, Zhou J (2013) Responses of soil moisture in different land cover types to rainfall events in a revegetation catchment area of the Loess Plateau, China. Catena 101:122-128

Wang TJ, Wedin DA, Franz TE, Hiller J (2015) Effect of vegetation on the temporal stability of soil moisture in grass-stabilized semi-arid sand dunes. J Hydrol 521:447-459

Wang S, Fu BJ, Gao GY, Zhou J, Jiao L, Liu J (2016) Linking the soil moisture distribution pattern to dynamic processes along slope transects in the Loess Plateau, China. Environ Monit Assess. doi:10.1007/s10661-015-5000-x

Yao XL, Fu BJ, Lu YH, Chang RY, Wang S et al (2012) The multiscale spatial variance of soil moisture in the semi-arid Loess Plateau of China. J Soils Sediments 12:694-703

Zhou J, Fu BJ, Gao GY, Lu N, Lu YH et al (2015) Temporal stability of surface soil moisture of different vegetation types in the Loess Plateau of China. Catena 128:1-15 